\title{
The effects of maternal body mass index and plurality on maternal and umbilical cord serum magnesium levels in preterm birth at less than 32 weeks of gestation
}

\author{
Yun Sun Choi, MD'1, Ji Young Hong, MD', Jee Youn Hong, MD¹, Yoo-Min Kim, MD², Ji-Hee Sung, MD1, \\ Suk-Joo Choi, MD, PhD'1, Soo-young Oh, MD, PhD ${ }^{1}$, Cheong-Rae Roh, MD, PhD ${ }^{1}$, Hye Seon Kim, MD³, \\ Se In Sung, MD, PhD ${ }^{3}$, So Yoon Ahn, MD, PhD ${ }^{3}$, Yun Sil Chang, MD, PhD

\begin{abstract}
Department of Obstetrics and Gynecology, ${ }^{1}$ Samsung Medical Center, Sungkyunkwan University School of Medicine, ${ }^{2}$ Chung-Ang University Hospital, Chung-Ang University College of Medicine; ${ }^{3}$ Department of Pediatrics, Samsung Medical Center, Sungkyunkwan University School of Medicine, Seoul, Korea
\end{abstract}

\section{Objective}

To evaluate the effects of maternal body mass index (BMI) and plurality on maternal and umbilical cord serum magnesium levels after antenatal magnesium sulfate treatment.

\section{Methods}

This was a retrospective cohort analysis of 135 women treated with antenatal magnesium sulfate at less than 32 weeks of gestation between January 2012 and June 2018. Subjects were stratified into groups according to maternal BMI (group I [18.5-22.9 kg/m²], group II [23.0-24.9 kg/m²], and group III [ $\left.\geq 25.0 \mathrm{~kg} / \mathrm{m}^{2}\right]$ ) and plurality (singleton and twin). Univariable and multivariable analyses were performed to compare the umbilical cord serum magnesium levels between the groups.

Results

Maternal serum magnesium levels were not significantly different between the maternal BMI groups and singleton and twin pregnancies. Umbilical cord serum magnesium levels were significantly different among the maternal BMI groups $(3.3 \pm 1.2 \mathrm{mg} / \mathrm{dL}$ in group I, $3.3 \pm 1.2 \mathrm{mg} / \mathrm{dL}$ in group II, and $4.0 \pm 1.4 \mathrm{mg} / \mathrm{dL}$ in group III, $P=0.003)$. The trend of increase in magnesium levels was statistically significant $(P=0.001$, Jonckheere-Terpstra test). Umbilical cord serum magnesium levels were not significantly different according to plurality. However, in the multivariable analysis, maternal BMI and plurality were not significantly associated with umbilical cord serum magnesium levels after adjusting for indication and total dose of magnesium sulfate treatment, gestational age at delivery, mode of delivery, neonatal sex, and birth weight.

\section{Conclusion}

Maternal BMI and plurality were not significantly associated with maternal or umbilical cord serum magnesium levels after exposure to antenatal magnesium sulfate treatment.

Keywords: Obesity; Twin; Magnesium sulfate; Preterm birth

\section{Introduction}

Magnesium sulfate is one of the most commonly prescribed medications in obstetrics. Over the past century, magnesium sulfate has been used as a tocolytic agent for the prevention and treatment of eclampsia and fetal neuroprotection
Received: 2020.08.12. Revised: 2020.09.29. Accepted: 2020.10.21.

Corresponding author: Suk-Joo Choi, $\mathrm{MD}, \mathrm{PhD}$

Department of Obstetrics and Gynecology, Samsung Medical Center, Sungkyunkwan University School of Medicine, 81 Irwonro, Gangnam-gu, Seoul 06351, Korea

E-mail: drmaxmix.choi@samsung.com https://orcid.org/0000-0002-8946-4789

Cheong-Rae Roh has been an Editorial Board of Obstetrics \& Gynecology Science; however, he was not involved in the peer reviewer selection, evaluation, or decision process of this article. Otherwise, no other potential conflicts of interest relevant to this article was reported.

Articles published in Obstet Gynecol Sci are open-access, distributed under the terms of the Creative Commons Attribution Non-Commercial License (http://creativecommons org/licenses/by-nc/3.0/) which permits unrestricted non-commercial use, distribution, and reproduction in any medium, provided the original work is properly cited.

Copyright $\odot 2021$ Korean Society of Obstetrics and Gynecology 


\section{Obstetrics \& Gynecology Science}

Yun Sun Choi, et al. Mg levels according to BMI and plurality

[1]. In the United States, more than 700,000 newborns are exposed to antenatal magnesium sulfate per year [2]. Since it is commonly used, there is a large body of academic research examining the protocols, therapeutic effects, and side effects of magnesium sulfate [2,3]. However, concerns about safety and the potential toxicity of magnesium sulfate on mothers and fetuses remain.

Maternal side effects of magnesium sulfate treatment, such as flushing, sweating, respiratory depression, muscular paralysis, tetany, hypotension, depressed reflexes, and cardiac arrest, are known to be related to the maternal serum level of magnesium sulfate $[4,5]$. Fetal and neonatal side effects of magnesium therapy include lethargy, hypotonia, respiratory depression, bone demineralization, and increased risk of intraventricular hemorrhage and neonatal mortality [6]. These risks are known to increase with high doses or long-term use of drugs [7-11].

Magnesium concentrations can be affected by various factors. The maternal body undergoes extensive physiologic changes during pregnancy, altering the pharmacokinetics and pharmacodynamic profiles of drugs. Maternal blood volume increases by an average of $40-45 \%$ during pregnancy, and it is more pronounced during twin pregnancy [12]. These changes can affect the drug's concentration in the body and, similarly, obesity can affect the volume of medication distribution. There have been several reports on the effect of maternal body mass index (BMI) and plurality on maternal or fetal/neonatal serum magnesium levels, but the results are inconclusive [13-17]. Moreover, there has been no study investigating the effects of plurality and $\mathrm{BMI}$ on maternal or fetal serum magnesium levels in the Korean population. Therefore, we evaluated the effects of plurality and maternal BMI on maternal and umbilical cord serum magnesium levels after antenatal magnesium sulfate treatment.

\section{Materials and methods}

\section{Study population and data collection}

This was a retrospective cohort study of 135 pregnant women and their 153 neonates exposed to antenatal magnesium sulfate treatment and born at less than 32 weeks of gestation at a tertiary referral center in Seoul, Korea, between January 2012 and June 2018. Fetal death and major congenital anomalies were excluded.
Medical records of mothers and neonates were reviewed independently by obstetricians and neonatologists. Researchers blinded to maternal data, including the antenatal magnesium sulfate treatment, reviewed the neonatal data for the outcome. Maternal demographic characteristics included maternal age, BMI at magnesium sulfate treatment, parity, and plurality. Subjects were classified into 3 groups according to BMl using the definition of the World Health Organization Asia-Pacific Perspective [18]: group I, $18.5-22.9 \mathrm{~kg} / \mathrm{m}^{2}$ (normal); group II, $23.0-24.9 \mathrm{~kg} / \mathrm{m}^{2}$ (overweight), and group III, $\geq 25.0 \mathrm{~kg} / \mathrm{m}^{2}$ (obese). Subjects were reclassified into 2 groups according to plurality as a singleton and twin pregnancies. One woman who was underweight $\left(\mathrm{BMl}<18.5 \mathrm{~kg} / \mathrm{m}^{2}\right)$ and 2 women with triplet pregnancies were excluded because the sample size was too small.

The antenatal treatments investigated were indications for antenatal magnesium sulfate treatment, total dose of magnesium sulfate use, and the type and cycle of antenatal corticosteroid treatment. Pregnancy outcomes included gestational age at delivery, indications for preterm delivery, and mode of delivery. Indications for preterm delivery were classified into preterm labor, preterm premature rupture of membranes, and maternal-fetal indications such as pre-eclampsia, placenta previa, placenta abruption, and intrauterine growth restriction.

Neonatal outcomes included birth weight, sex, Apgar scores, mortality, necrotizing enterocolitis ( $\geq$ stage $2 b$ ), spontaneous intestinal perforation, duration of neonatal intensive care unit admission, duration of ventilator treatment, respiratory distress syndrome, moderate to severe bronchopulmonary dysplasia, intraventricular hemorrhage (IVH) ( $\geq$ grade 3), periventricular leukomalacia, early- and late-onset neonatal sepsis, retinopathy of prematurity ( $\geq$ grade 3 ), and patent ductus arteriosus.

\section{Magnesium sulfate treatment and magnesium level measurement protocol}

Indications of antenatal magnesium sulfate treatment were fetal neuroprotection and severe pre-eclampsia. The magnesium sulfate treatment protocol consisted of an intravenous loading dose of $4 \mathrm{~g}$ over 15 to 20 minutes, followed by a maintenance infusion of $1 \mathrm{~g}$ per hour. For fetal neuroprotection, magnesium sulfate was started for women with imminent preterm birth within 24 hours. A maintenance dose was infused until delivery if delivery occurred within 24 hours, 


\section{Obstetrics \& Gynecology Science}

Vol. 64, No. 1, 2021

but it was discontinued if the delivery did not occur within 24 hours and was no longer considered imminent. The maintenance dose was resumed if the risk of imminent delivery recurred within 6 hours. A repeat loading dose and subsequent maintenance therapy were administered if the risk of imminent delivery recurred after 6 hours. To treat severe

Table 1. Maternal characteristics, antenatal treatments and pregnancy outcomes according to maternal body mass index

\begin{tabular}{|c|c|c|c|c|}
\hline Characteristics & Group I $(n=32)$ & Group II $(n=28)$ & Group III $(n=75)$ & $P$-value ${ }^{\text {a) }}$ \\
\hline Age (yr) & $32.5 \pm 4.2$ & $33.4 \pm 4.5$ & $34.2 \pm 3.5$ & $0.099^{b)}$ \\
\hline $\mathrm{BMI}\left(\mathrm{kg} / \mathrm{m}^{2}\right)$ & $21.2 \pm 1.0$ & $23.8 \pm 0.8$ & $29.4 \pm 3.5$ & $<0.001^{b, c, d, e)}$ \\
\hline Multiparity & $13(40.6)$ & $8(28.6)$ & $22(29.3)$ & 0.474 \\
\hline Plurality & & & & 0.579 \\
\hline Singleton & $26(81.3)$ & $25(89.3)$ & $66(88.0)$ & \\
\hline Twin & $6(18.8)$ & $3(10.7)$ & $9(12.0)$ & \\
\hline Gestational age at $\mathrm{MgSO}_{4}$ treatment (wk) & $27.9 \pm 2.6$ & $27.6 \pm 2.5$ & $27.5 \pm 2.7$ & 0.764 \\
\hline Indication for $\mathrm{MgSO}_{4}$ treatment & & & & $<0.001^{b, c, d, e)}$ \\
\hline Neuroprotection & $28(87.5)$ & $18(64.3)$ & $24(32.0)$ & \\
\hline Severe preeclampsia & $4(12.5)$ & $10(35.7)$ & $51(68.0)$ & \\
\hline Total dose of $\mathrm{MgSO}_{4}(\mathrm{~g})$ & $4(4-198)$ & $4(4-185)$ & $22(4-482)$ & $<0.001^{\mathrm{b})}$ \\
\hline Maternal serum Mg level & $4.4 \pm 1.4$ & $4.8 \pm 1.5$ & $4.5 \pm 1.2$ & 0.808 \\
\hline $\begin{array}{l}\text { Interval from } \mathrm{MgSO}_{4} \text { treatment to } \mathrm{Mg} \text { level } \\
\text { measurement }(\mathrm{hr})\end{array}$ & $12(4-35)$ & $19(11-113)$ & $14(5-106)$ & 0.308 \\
\hline Antenatal corticosteroids use & $30(93.8)$ & $27(96.4)$ & $68(90.7)$ & 0.586 \\
\hline Type of corticosteroids & & & & 0.869 \\
\hline Betamethasone & $29(96.7)$ & $26(96.3)$ & $63(92.6)$ & \\
\hline Dexamethasone & $1(3.3)$ & $1(3.7)$ & $4(5.9)$ & \\
\hline Mixed $^{f)}$ & $0(0.0)$ & $0(0.0)$ & $1(1.5)$ & \\
\hline Cycles of corticosteroids & & & & 0.983 \\
\hline Incomplete cycle & $6(20.0)$ & $4(14.8)$ & $12(17.6)$ & \\
\hline Complete cycle & $20(66.7)$ & $20(74.1)$ & $48(70.6)$ & \\
\hline Multiple cycles & $4(13.3)$ & $3(11.1)$ & $8(11.8)$ & \\
\hline Gestational age at delivery (wk) & $28.0 \pm 2.5$ & $27.8 \pm 2.6$ & $27.9 \pm 2.5$ & 0.947 \\
\hline$<26$ & $8(25.0)$ & $7(25.0)$ & $15(20.0)$ & 0.786 \\
\hline$<28$ & $15(46.9)$ & $13(46.4)$ & $38(50.7)$ & 0.898 \\
\hline$<30$ & $22(68.8)$ & $20(71.4)$ & $55(73.3)$ & 0.889 \\
\hline Indication for preterm delivery & & & & $<0.001^{b, c, e)}$ \\
\hline PTL & $10(31.3)$ & $8(28.6)$ & $14(18.7)$ & \\
\hline PPROM & $14(43.8)$ & $4(14.3)$ & $10(13.3)$ & \\
\hline Maternal-fetal indication & $8(25.0)$ & $16(57.1)$ & $51(68.0)$ & \\
\hline Cesarean delivery & $19(59.4)$ & $27(96.4)$ & $61(81.3)$ & $0.002^{b, c, e)}$ \\
\hline
\end{tabular}

Data are presented as number (percentage), mean \pm standard deviation or median (range).

$\mathrm{BMI}$, body mass index; $\mathrm{MgSO}_{4}$, magnesium sulfate; Mg, magnesium; PTL, preterm labor; PPROM, preterm premature rupture of membranes.

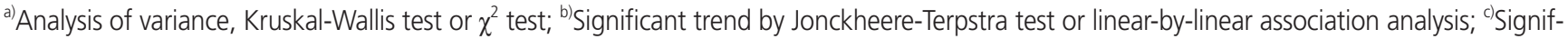

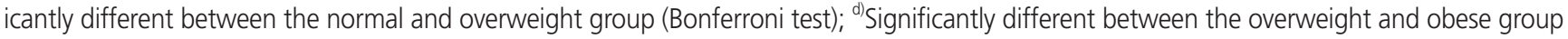

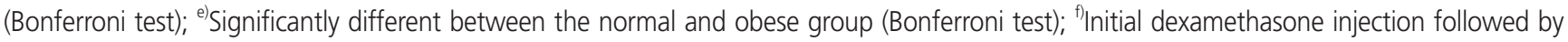
rescue betamethasone injection. 


\section{Obstetrics \& Gynecology Science}

Yun Sun Choi, et al. Mg levels according to BMI and plurality

pre-eclampsia and eclampsia, a maintenance dose was infused until delivery and discontinued 24 hours after delivery. Magnesium sulfate was not used for tocolytics in our hospital. Women treated with magnesium sulfate as tocolytics in other hospitals and transferred to our hospital were excluded because the exact protocol of magnesium sulfate treatment, including dose and duration, was unknown.

Maternal and umbilical cord serum magnesium levels were measured in the hospital laboratory by the endpoint calorimetric method using xylidyl blue (Cobas c 702; Roche Diagnostics, Basel, Switzerland). The first maternal serum magnesium level measured after magnesium sulfate infusion was used for the analysis, and the time interval from magnesium sulfate treatment (loading dose) to the first maternal serum magnesium level measurement was calculated. Fetal magnesium and calcium concentrations were measured in the umbilical cord serum collected immediately after delivery.

\section{Statistical analysis}

The primary outcomes of this study were maternal and umbilical cord serum magnesium levels. Continuous variables were compared using independent-sample parametric (Student's $t$-test for comparison between 2 groups and analysis of variance for comparison among 3 groups) or nonparametric (Mann-Whitney $U$ test for comparison between 2 groups and Kruskal-Wallis test for comparison among 3 groups) tests depending on data normality. Categorical variables were compared using the $\chi^{2}$ test or Fisher's exact test when

Table 2. Neonatal outcomes according to maternal body mass index

\begin{tabular}{|c|c|c|c|c|}
\hline Characteristics & Group I $(n=38)$ & Group II $(n=31)$ & Group III $(n=84)$ & $P$-value ${ }^{\text {a) }}$ \\
\hline Birth weight $(\mathrm{kg})$ & $1.07 \pm 0.41$ & $0.96 \pm 0.40$ & $0.97 \pm 0.39$ & 0.371 \\
\hline Male & $21(55.3)$ & $15(48.4)$ & $36(42.9)$ & 0.440 \\
\hline 1-min Apgar score $<4$ & $5(13.2)$ & $10(32.3)$ & $14(16.7)$ & 0.096 \\
\hline 5-min Apgar score $<7$ & $4(10.5)$ & $8(25.8)$ & $14(16.7)$ & 0.242 \\
\hline Mg level (mg/dL) & $3.3 \pm 1.2$ & $3.3 \pm 1.2$ & $4.0 \pm 1.4$ & $0.003^{b, c, d)}$ \\
\hline Ca level (mg/dL) & $10.0 \pm 0.9$ & $9.7 \pm 1.0$ & $9.4 \pm 1.1$ & $0.012^{\mathrm{b}, \mathrm{c}}$ \\
\hline NEC ( $\geq$ stage $2 b$ ) & $1(2.6)$ & $1(3.2)$ & $9(9.5)$ & 0.255 \\
\hline SIP & 0 & $1(3.2)$ & $3(3.6)$ & 0.505 \\
\hline Mortality & $4(10.5)$ & $5(16.1)$ & $12(14.3)$ & 0.778 \\
\hline NICU stay duration (day) & $80(2-364)$ & $61(5-185)$ & $78(2-250)$ & 0.895 \\
\hline Ventilator & $34(89.5)$ & $30(96.8)$ & $77(91.7)$ & 0.517 \\
\hline Ventilator use duration (day) & $32(1-276)$ & $37(1-154)$ & $34.5(1-276)$ & 0.941 \\
\hline RDS & $31(81.6)$ & $30(96.8)$ & $76(90.5)$ & 0.112 \\
\hline BPD (moderate or severe) & $12(35.3)$ & $7(25.0)$ & $19(24.7)$ & 0.488 \\
\hline IVH ( $\geq$ grade 3) & $4(10.8)$ & $3(9.7)$ & $7(8.5)$ & 0.923 \\
\hline PVL & $1(2.7)$ & 0 & $5(6.1)$ & 0.302 \\
\hline Sepsis & $5(13.2)$ & $2(6.5)$ & $11(13.1)$ & 0.589 \\
\hline Early onset of sepsis & $1(2.6)$ & $1(3.2)$ & $2(2.4)$ & 0.969 \\
\hline Late onset of sepsis & $4(10.8)$ & $1(3.3)$ & $9(11.3)$ & 0.431 \\
\hline ROP ( $\geq$ grade 3 ) & $7(20.6)$ & $4(14.3)$ & $16(20.5)$ & 0.755 \\
\hline PDA & $23(62.2)$ & $23(74.2)$ & $53(63.1)$ & 0.492 \\
\hline
\end{tabular}

Data are presented as number (percentage), mean \pm standard deviation or median (range).

Mg, magnesium; Ca, calcium; NEC, necrotizing enterocolitis; SIP, spontaneous intestinal perforation; NICU, neonatal intensive care unit; RDS, respiratory distress syndrome; BPD, bronchopulmonary dysplasia; IVH, intraventricular hemorrhage; PVL, periventricular leukomalacia; ROP, retinopathy of prematurity; PDA, patent ductus arteriosus.

${ }^{a}$ Analysis of variance, Kruskal-Wallis test or $\chi^{2}$ test; $\left.{ }^{b}\right)$ Significant trend by Jonckheere-Terpstra test or linear-by-linear association analysis; ${ }^{~}$ Signif-

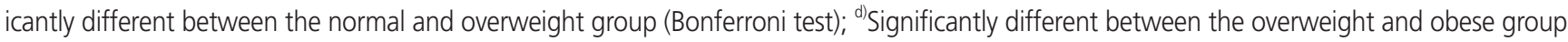
(Bonferroni test). 


\title{
Obstetrics \& Gynecology Science
}

\author{
Vol. 64 , No. 1, 2021
}

one or more expected values were less than 5 . The Bonferroni test was used for post hoc analysis to correct for multiple comparisons. The trend was analyzed using the JonckheereTerpstra test for continuous variables and linear-by-linear association analysis for categorical variables. Multivariable linear regression analysis was used to evaluate the effects of potential confounding variables including an indication of magnesium sulfate treatment, gestational age at magnesium sulfate treatment, the interval from magnesium sulfate treatment to magnesium level measurement, the total dose of magnesium sulfate infused, maternal BMI, and plurality for maternal serum magnesium level, gestational age at delivery, mode of delivery, neonatal sex, birth weight, maternal BMI, and plurality for umbilical cord serum magnesium level. A Pvalue of less than 0.05 was considered statistically significant. For multiple comparisons, the $P$-value was adjusted to 0.017

Table 3. Maternal characteristics, antenatal treatments and pregnancy outcomes according to plurality

\begin{tabular}{|c|c|c|c|}
\hline Characteristics & Singleton $(n=117)$ & Twin $(n=18)$ & $P$-value ${ }^{\text {a) }}$ \\
\hline Age (yr) & $33.7 \pm 4.1$ & $33.4 \pm 2.7$ & 0.775 \\
\hline BMI $\left(k g / m^{2}\right)$ & $26.4 \pm 4.6$ & $25.7 \pm 3.7$ & 0.519 \\
\hline Multiparity & $42(35.9)$ & $1(5.6)$ & 0.010 \\
\hline Gestational age at $\mathrm{MgSO}_{4}$ treatment (wk) & $27.7 \pm 2.6$ & $27.5 \pm 3.1$ & 0.780 \\
\hline Indication for $\mathrm{MgSO}_{4}$ treatment & & & 0.177 \\
\hline Neuroprotection & $58(49.6)$ & $12(66.7)$ & \\
\hline Severe preeclampsia & $59(50.4)$ & $6(33.3)$ & \\
\hline Total dose of $\mathrm{MgSO}_{4}(\mathrm{~g})$ & $7.5(4-482)$ & $4.0(4-88)$ & 0.405 \\
\hline Maternal serum Mg level & $4.5 \pm 1.3$ & $5.0 \pm 0.5$ & 0.369 \\
\hline $\begin{array}{l}\text { Interval from } \mathrm{MgSO}_{4} \text { treatment to Mg level } \\
\text { measurement (hr) }\end{array}$ & $14.5(5-113)$ & $16(4-47)$ & 0.957 \\
\hline Antenatal corticosteroids use & $107(91.5)$ & $18(100)$ & 0.358 \\
\hline Type of corticosteroids & & & 0.371 \\
\hline Betamethasone & $102(95.3)$ & $16(88.9)$ & \\
\hline Dexamethasone & $4(3.7)$ & $2(11.1)$ & \\
\hline Mixed $^{b}$ & $1(0.9)$ & 0 & \\
\hline Cycles of corticosteroids & & & 0.367 \\
\hline Incomplete cycle & $17(15.9)$ & $5(27.8)$ & \\
\hline Complete cycle & $76(71.0)$ & $12(66.7)$ & \\
\hline Multiple cycles & $14(13.1)$ & $1(5.6)$ & \\
\hline Gestational age at delivery (wk) & $28.0 \pm 2.4$ & $27.6 \pm 3.1$ & 0.598 \\
\hline$<26$ & $24(20.5)$ & $6(33.3)$ & 0.232 \\
\hline$<28$ & $56(47.9)$ & $10(55.6)$ & 0.543 \\
\hline$<30$ & $86(73.5)$ & $11(61.1)$ & 0.276 \\
\hline Indication for preterm delivery & & & 0.214 \\
\hline PTL & $25(21.4)$ & $7(38.9)$ & \\
\hline PPROM & $24(20.5)$ & $4(22.2)$ & \\
\hline Maternal-fetal indication & $68(58.1)$ & $7(38.9)$ & \\
\hline Cesarean delivery & $90(76.9)$ & $17(94.4)$ & 0.120 \\
\hline
\end{tabular}

Data are presented as number (percentage), mean \pm standard deviation or median (range).

$\mathrm{BMI}$, body mass index; $\mathrm{MgSO}_{4}$, magnesium sulfate; Mg, magnesium; PTL, preterm labor; PPROM, preterm premature rupture of membranes. ${ }^{a}$ Student's $t$-test, Mann-Whitney $U$ test, $\chi^{2}$ test or Fisher's exact test; ${ }^{b}$ Initial dexamethasone injection followed by rescue betamethasone injection. 


\section{Obstetrics \& Gynecology Science}

Yun Sun Choi, et al. Mg levels according to BMI and plurality

$(0.05 / 3)$ by Bonferroni correction. All statistical analyses were performed using the Statistical Package for Social Sciences version 25 (SPSS Statistics; IBM, Armonk, NY, USA).

\section{Results}

A total of 135 women (153 neonates) were included in this study. There were 32 women (38 neonates) in group I, 28 (31 neonates) women in group II, and 75 (84 neonates) women in group III. Among the 135 women, 117 were singleton pregnant women (117 neonates), and 18 were twin pregnant women (36 neonates).

The baseline maternal characteristics, antenatal treatments, and pregnancy outcomes according to maternal BMI are shown in Table 1. Indications for magnesium sulfate treatment, indications for preterm delivery, and mode of delivery were significantly different among the 3 groups. The total doses of magnesium sulfate infused were significantly different among the 3 groups ( $P<0.001$, analysis of variance), and they increased significantly with increasing maternal BMI $(P<0.001$, Jonckheere-Terpstra test). However, the interval from magnesium sulfate treatment to magnesium level measurement and maternal serum magnesium levels were not significantly different among the 3 groups.

Neonatal outcomes, according to maternal BMI, are presented in Table 2. Umbilical cord serum magnesium levels were significantly different among the 3 groups $(3.3 \pm 1.2 \mathrm{mg} /$ $\mathrm{dL}$ in group I; $3.3 \pm 1.2 \mathrm{mg} / \mathrm{dL}$ in group $\mathrm{ll}$; and $4.0 \pm 1.4 \mathrm{mg} / \mathrm{dL}$ in group III; $P=0.003$, Kruskal-Wallis test), and they increased

Table 4. Neonatal outcomes according to plurality

\begin{tabular}{|c|c|c|c|}
\hline Characteristics & Singleton $(n=117)$ & Twin $(n=36)$ & $P$-value ${ }^{\text {a) }}$ \\
\hline Birth weight $(\mathrm{kg})$ & $1.0 \pm 0.4$ & $1.0 \pm 0.4$ & 0.619 \\
\hline Male & $64(54.7)$ & $17(47.2)$ & 0.432 \\
\hline 1-min Apgar score<4 & $21(17.9)$ & $8(22.2)$ & 0.567 \\
\hline 5-min Apgar score $<7$ & $16(13.7)$ & $10(27.8)$ & 0.049 \\
\hline Mg level (mg/dL) & $3.7 \pm 1.4$ & $3.5 \pm 1.4$ & 0.431 \\
\hline Ca level (mg/dL) & $9.7 \pm 1.0$ & $9.6 \pm 1.1$ & 0.702 \\
\hline NEC ( $\geq$ stage $2 b)$ & $6(5.1)$ & $4(11.1)$ & 0.246 \\
\hline SIP & $3(2.6)$ & $1(2.8)$ & $>0.999$ \\
\hline Mortality & $13(11.1)$ & $8(22.2)$ & 0.102 \\
\hline NICU stay duration (day) & $76(2-250)$ & $68.5(2-364)$ & 0.943 \\
\hline Ventilator & $109(93.2)$ & $32(88.9)$ & 0.478 \\
\hline Ventilator use duration (day) & $32(1-223)$ & $36(1-276)$ & 0.590 \\
\hline RDS & $106(90.6)$ & $31(86.1)$ & 0.533 \\
\hline BPD (moderate or severe) & $27(25.0)$ & $11(35.5)$ & 0.248 \\
\hline IVH ( $\geq$ grade 3 ) & $7(6.1)$ & $7(20.0)$ & 0.021 \\
\hline PVL & $6(5.2)$ & 0 & 0.337 \\
\hline Sepsis & $13(11.1)$ & $5(13.9)$ & 0.767 \\
\hline Early onset of sepsis & $4(3.4)$ & 0 & 0.573 \\
\hline Late onset of sepsis & $9(8.0)$ & $5(14.7)$ & 0.315 \\
\hline ROP ( $\geq$ grade 3 ) & $18(16.5)$ & $9(29.0)$ & 0.119 \\
\hline PDA & $79(68.1)$ & $20(55.6)$ & 0.168 \\
\hline
\end{tabular}

Data are presented as number (percentage), mean \pm standard deviation or median (range).

Mg, magnesium; Ca, calcium; NEC, necrotizing enterocolitis; SIP, spontaneous intestinal perforation; NICU, neonatal intensive care unit; RDS, respiratory distress syndrome; BPD, bronchopulmonary dysplasia; IVH, intraventricular hemorrhage; PVL, periventricular leukomalacia; ROP, retinopathy of prematurity; PDA, patent ductus arteriosus.

${ }^{a}$ Student's $t$-test, Mann-Whitney $U$ test, $\chi^{2}$ test or Fisher's exact test. 


\title{
Obstetrics \& Gynecology Science
}

\author{
Vol. 64, No. 1, 2021
}

significantly with increasing maternal $\mathrm{BMl}$ groups $(P=0.001$, Jonckheere-Terpstra test). Umbilical cord serum calcium levels were significantly different among the 3 groups $(P=0.012$, Kruskal-Wallis test), and they decreased significantly with maternal BMI ( $P=0.001$, Jonckheere-Terpstra test). Other neonatal outcomes were similar among the 3 groups.

Baseline maternal characteristics, antenatal treatments, and pregnancy outcomes were not significantly different between the singleton and twin groups except for parity (Table 3). The total dose of magnesium sulfate infused, the interval from magnesium sulfate treatment to magnesium level measurement, and maternal serum magnesium levels were comparable between the singleton and twin groups. The umbilical cord serum magnesium levels $(3.7 \pm 1.4 \mathrm{mg} / \mathrm{dL}$ in singletons and $3.7 \pm 1.4 \mathrm{mg} / \mathrm{dL}$ in twins; $P=0.431$ ) were not significantly different between the singleton and twin groups (Table 4). Neonatal outcomes were comparable between the 2 groups, except for a higher rate of 1-minute Apgar score $<7$, and a higher rate of IVH ( $\geq$ grade 3 ) in the twin group than in the singleton group.

In the multivariable linear regression analyses, maternal serum magnesium levels were not associated with maternal BMI ( $\beta$ : $-0.203 ; 95 \%$ confidence interval $[\mathrm{Cl}],-0.123-0.015$;
$P=0.121)$ or plurality $(\beta: 0.089 ; 95 \% \mathrm{Cl},-0.652-1.389$; $P=0.472$ ) after adjusting for the indication of magnesium sulfate treatment, gestational age at magnesium sulfate treatment, the interval from magnesium sulfate treatment to magnesium level measurement, and total dose of magnesium sulfate infused (Table 5). Indication of magnesium sulfate treatment was the only significant factor associated with maternal serum magnesium level. Umbilical cord serum magnesium levels were not also associated with maternal BMI ( $\beta$ : $-0.046 ; 95 \% \mathrm{Cl},-0.294-0.145 ; P=0.501$ ) and a plurality ( $\beta$ : $0.054 ; 95 \% \mathrm{Cl},-0.226-0.596 ; P=0.375$ ) after adjusting for the indication of magnesium sulfate treatment, the total dose of magnesium sulfate infused, gestational age at delivery, mode of delivery, neonatal sex, and birth weight (Table 5). Indication of magnesium sulfate treatment, gestational age at delivery, neonatal sex, and birth weight were significantly associated with umbilical cord serum magnesium levels.

We analyzed the maternal and umbilical cord serum magnesium levels according to maternal BMI and plurality in women with pre-eclampsia. Maternal serum magnesium levels $(5.0 \pm 0.5 \mathrm{mg} / \mathrm{dL}$ in group l; $4.9 \pm 1.3 \mathrm{mg} / \mathrm{dL}$ in group II; and $4.6 \pm 1.1 \mathrm{mg} / \mathrm{dL}$ in group III; $P=0.411$, Kruskal-Wallis test), and umbilical cord serum magnesium levels $(5.6 \pm 1.4 \mathrm{mg} / \mathrm{dL}$ in the

Table 5. Multiple linear regression analyses of maternal and umbilical cord blood serum magnesium levels controlling for potential confounding variables

\begin{tabular}{|c|c|c|}
\hline Variables & $\beta(95 \% \mathrm{Cl})$ & $P$-value \\
\hline \multicolumn{3}{|l|}{ Maternal serum Mg level } \\
\hline Maternal BMI $\left(\mathrm{kg} / \mathrm{m}^{2}\right)$ & $-0.203(-0.123,0.015)$ & 0.121 \\
\hline Twin pregnancy & $0.089(-0.652,1.389)$ & 0.472 \\
\hline Indication of $\mathrm{MgSO}_{4}$ use & $0.326(0.344,2.914)$ & 0.014 \\
\hline Gestational age at $\mathrm{MgSO}_{4}$ treatment (wk) & $0.149(-0.006,0.025)$ & 0.241 \\
\hline Interval from $\mathrm{MgSO}_{4}$ treatment to $\mathrm{Mg}$ level measurement (hour) & $-0.014(-0.015,0.014)$ & 0.908 \\
\hline Total dose of $\mathrm{MgSO}_{4}(\mathrm{~g})$ & $-0.005(-0.003,0.003)$ & 0.969 \\
\hline \multicolumn{3}{|l|}{ Umbilical cord Mg level } \\
\hline Maternal BMI $\left(\mathrm{kg} / \mathrm{m}^{2}\right)$ & $-0.046(-0.294,0.145)$ & 0.501 \\
\hline Twin pregnancy & $0.054(-0.226,0.596)$ & 0.375 \\
\hline Indication of $\mathrm{MgSO}_{4}$ use & $0.691(1.491,2.355)$ & $<0.001$ \\
\hline Total dose of $\mathrm{MgSO}_{4}(\mathrm{~g})$ & $0.042(-0.002,0.004)$ & 0.543 \\
\hline Gestational age at delivery (wk) & $0.227(0.002,0.035)$ & 0.030 \\
\hline Cesarean section & $-0.077(-0.738,0.197)$ & 0.254 \\
\hline Neonatal sex (male) & $-0.130(-0.707,-0.013)$ & 0.042 \\
\hline Birth weight $(\mathrm{kg})$ & $-0.234(-1.571,-0.084)$ & 0.029 \\
\hline
\end{tabular}

$\mathrm{Cl}$, confidence interval; $\mathrm{Mg}$, magnesium; $\mathrm{BMI}$, body mass index; $\mathrm{MgSO}_{4}$, magnesium sulfate. 


\section{Obstetrics \& Gynecology Science}

Yun Sun Choi, et al. Mg levels according to BMI and plurality

group I; $4.3 \pm 1.2 \mathrm{mg} / \mathrm{dL}$ in the group Il; and $4.7 \pm 1.2 \mathrm{mg} / \mathrm{dL}$ in the group III; $P=0.259$, Kruskal-Wallis test) were not significantly different among the $3 \mathrm{BMI}$ groups. Maternal serum magnesium levels $(4.6 \pm 1.2 \mathrm{mg} / \mathrm{dL}$ in the singletons; $5.0 \pm 0.5 \mathrm{mg} / \mathrm{dL}$ in the twins; $P=0.332$, Mann-Whitney $U$ test), and umbilical cord serum magnesium levels $(4.7 \pm 1.3 \mathrm{mg} / \mathrm{dL}$ in the singletons; $5.0 \pm 1.1 \mathrm{mg} / \mathrm{dL}$ in the twins; $P=0.246$, Mann-Whitney $U$ test) were not significantly different between singletons and twins.

\section{Discussion}

This study was conducted to investigate the relationship between maternal BMI and plurality in maternal and umbilical cord serum magnesium levels after treatment with antenatal magnesium sulfate. Maintaining an adequate magnesium level during magnesium sulfate therapy remains challenging because it can be varied by various factors such as BMI, plurality, and indications of its use. The main finding of this study is that maternal BMI and plurality were not associated with maternal or umbilical cord serum magnesium levels after antenatal magnesium sulfate treatment.

Achieving a therapeutic concentration of magnesium sulfate while avoiding potential toxicity requires knowledge of magnesium in circulation. If magnesium sulfate is injected intramuscularly, the plasma concentration reaches a plateau within 1-2 hours and gradually decreases to the baseline level over the subsequent 6-8 hours [19]. When magnesium sulfate is administered parenterally, it is initially distributed in intravascular compartments. Then, unbound magnesium ions in the blood vessels spread across the extravascular-extracellular spaces. It also diffuses across the placenta and fetal membranes into the fetus and amniotic fluid [20]. When pregnant women receive magnesium sulfate infusions of 1-2 $\mathrm{g} / \mathrm{h}$, fetal serum magnesium levels rise twice as high as the baseline. The highest concentration is observed in the umbilical vein arterial blood [21]. Magnesium sulfate is not metabolized but is excreted by the maternal kidney, representing the only elimination route. The half-life of magnesium sulfate in patients with normal kidney function is 4 hours, and it increases when the glomerular filtration rate decreases. Four hours later, $38-53 \%$ of the total injected magnesium was excreted. After 24 hours of administration, more than $90 \%$ was removed [22].
Previous studies have reported an inverse relationship between maternal BMI and serum magnesium levels $[13,14]$. Dayicioglu et al. [13] reported that maternal serum magnesium levels at 2 hours after treatment initiation were inversely related to maternal BMI. Nakazawa et al. [14] also reported that the maternal serum magnesium level decreased with increase in maternal body weight. This negative correlation was consistently found in both singleton and twins but was stronger in twins. Tudela et al. [16] reported that obese women had an increased risk of having a subtherapeutic serum magnesium level when measured 4 hours after the beginning of treatment. However, only $5 \%$ of obese women with a subtherapeutic level had a subtherapeutic level after 12 hours. However, our study showed that maternal serum magnesium levels were not affected by maternal BMI. The discrepancy between the results of previous studies and ours might be due to different time intervals between magnesium sulfate treatment and maternal serum magnesium level measurements. While maternal serum magnesium levels were measured at short and constant intervals ( 2 or 4 hours) after the initiation of treatment in previous studies $[13,16]$, the maternal serum magnesium levels were measured at longer and more variable time intervals in our study. In addition, the study population in our study was more heterogeneous than in previous studies in terms of indication for magnesium sulfate treatment. We included patients treated with antenatal magnesium sulfate for fetal neuroprotection and severe preeclampsia and indications for the use of magnesium sulfate, and the total doses of magnesium sulfate infused were significantly different among the $3 \mathrm{BMI}$ groups. The duration of magnesium sulfate treatment is usually longer; therefore, the total dose of magnesium sulfate infused is higher when used for severe pre-eclampsia than that used for fetal neuroprotection. The proportion of magnesium sulfate treatment for severe pre-eclampsia increased but decreased for fetal neuroprotection treatment with increased maternal BMI. Therefore, we performed a multivariable analysis, but maternal serum magnesium levels were not associated with maternal $\mathrm{BMI}$ or plurality after adjusting for the indication of magnesium sulfate treatment, the total dose of magnesium sulfate infused, and gestational age at delivery.

In our study, maternal BMI was not associated with umbilical cord serum magnesium levels. This is similar to previous studies investigating the association between antenatal magnesium sulfate administration and the level of blood 


\section{Obstetrics \& Gynecology Science}

Vol. 64, No. 1, 2021

magnesium in the umbilicus $[15,23]$. Reynolds et al. [23] have shown that there was no relationship between the umbilical cord blood magnesium level and maternal BMI after adjusting for confounding factors, including the total dose of magnesium sulfate infused, similar to our study. In another study where magnesium sulfate was used for neuroprotection, there was a trend toward lower umbilical cord blood magnesium levels as maternal BMI increased, but this was not statistically significant [15].

The effect of plurality on maternal or umbilical cord serum magnesium levels has been relatively less studied, and the results are controversial. Elliott and Radin [24] have shown similar maternal serum magnesium levels following magnesium sulfate treatment for tocolysis in triplet and quadruplet pregnancies compared to singleton pregnancies. Our study also found that maternal serum magnesium levels were not significantly different between singleton and twin pregnancies. In contrast, a study that evaluated maternal serum magnesium levels according to the plurality of magnesium sulfate for fetal neuroprotection found that the maternal serum magnesium level in twin pregnancies was significantly lower than in singleton pregnancies [25]. In addition, the study showed that the rate of women who reached therapeutic levels at 6 hours after treatment began was lower in twin pregnancies than in singleton pregnancies [25]. The difference between these studies can be explained by differences in the study population, sample size, and timing of maternal serum magnesium measurements. To date, no study has evaluated the effect of plurality on umbilical cord serum magnesium levels after magnesium sulfate treatment. To the best of our knowledge, our study is the first to evaluate the effect of plurality on umbilical cord serum magnesium levels, and we found that umbilical cord serum magnesium levels were not significantly different between singleton and twin pregnancies.

This study should be appraised in light of the following limitations. First, this was a single-center, retrospective study, and therefore, the results might have been affected by confounding factors. Specifically, indication and gestational age at magnesium sulfate treatment, the interval from magnesium sulfate treatment to magnesium level measurement, and total dose of magnesium sulfate infused were highly variable. To compensate for this, we performed multivariable analyses to adjust for potential confounding factors, but there might be other unidentifiable factors that have af- fected our results. Second, our study may be underpowered because the sample size was not enough to show a difference in the outcomes, especially with fewer twin pregnancies. Lastly, we were unable to show a difference in clinical outcomes due to differences in serum magnesium concentrations, especially the long-term outcomes of the babies.

In conclusion, maternal and umbilical cord serum magnesium levels were not associated with maternal BMI and plurality after antenatal magnesium sulfate treatment. However, further prospective, well-designed studies with larger sample sizes are needed to uncover the effect of maternal BMI and plurality on maternal and umbilical cord serum magnesium levels and to assess whether dose adjustment is needed according to maternal BMI and plurality.

\section{Presentation}

This study was presented at the 66th Annual Scientific Meeting of the Society for Reproductive Investigation, Paris, France, March 12-16, 2019 (abstract \#F-063).

\section{Conflict of interest}

No potential conflict of interest relevant to this article was reported.

\section{Ethical approval}

This study was approved by the Institutional Review Board for Clinical Research in Samsung Medical Center (IRB No SMC 2019-04-051).

\section{Patient consent}

Informed consent was waived because of the retrospective study design.

\section{Funding information}

This study was supported in part by the Korea Health Tech- 


\section{Obstetrics \& Gynecology Science}

Yun Sun Choi, et al. Mg levels according to BMI and plurality

nology R\&D Project through the Korea Health Industry Development Institute (KHIDI), funded by the Ministry of Health \& Welfare, Republic of Korea (grant number: HI14C0306).

\section{References}

1. Pryde PG, Mittendorf R. Contemporary usage of obstetric magnesium sulfate: indication, contraindication, and relevance of dose. Obstet Gynecol 2009;114:669-73.

2. Brookfield KF, Su F, Elkomy MH, Drover DR, Lyell DJ, Carvalho B. Pharmacokinetics and placental transfer of magnesium sulfate in pregnant women. Am J Obstet Gynecol 2016;214:737.e1-9.

3. Okusanya BO, Oladapo OT, Long Q, Lumbiganon P, Carroli G, Qureshi Z, et al. Clinical pharmacokinetic properties of magnesium sulphate in women with preeclampsia and eclampsia. BJOG 2016;123:356-66.

4. Smith JM, Lowe RF, Fullerton J, Currie SM, Harris L, Felker-Kantor E. An integrative review of the side effects related to the use of magnesium sulfate for pre-eclampsia and eclampsia management. BMC Pregnancy Childbirth 2013;13:34.

5. Nassar AH, Sakhel K, Maarouf H, Naassan GR, Usta IM. Adverse maternal and neonatal outcome of prolonged course of magnesium sulfate tocolysis. Acta Obstet Gynecol Scand 2006;85:1099-103.

6. Rigo J, Pieltain C, Christmann V, Bonsante F, Moltu SJ, lacobelli $S$, et al. Serum magnesium levels in preterm infants are higher than adult levels: a systematic literature review and meta-analysis. Nutrients 2017;9:1125.

7. Kaplan W, Haymond MW, McKay S, Karaviti LP. Osteopenic effects of $\mathrm{MgSO} 4$ in multiple pregnancies. J Pediatr Endocrinol Metab 2006;19:1225-30.

8. Mittendorf R, Covert R, Elin R, Pryde PG, Khoshnood $B$, Lee K. Umbilical cord serum ionized magnesium level and total pediatric mortality. Obstet Gynecol 2001;98:75-8.

9. Mittendorf R, Dambrosia J, Dammann O, Pryde PG, Lee $\mathrm{KS}$, Ben-Ami TE, et al. Association between maternal serum ionized magnesium levels at delivery and neonatal intraventricular hemorrhage. J Pediatr 2002;140:540-6.

10. Mittendorf R, Dammann O, Lee KS. Brain lesions in newborns exposed to high-dose magnesium sulfate during preterm labor. J Perinatol 2006;26:57-63.
11. Yokoyama K, Takahashi N, Yada Y, Koike Y, Kawamata R, Uehara $R$, et al. Prolonged maternal magnesium administration and bone metabolism in neonates. Early Hum Dev 2010;86:187-91.

12. Cunningham F, Leveno K, Bloom S, Spong CY, Dashe J. Williams obstetrics. 24th ed. New York, NY: McgrawHill; 2014.

13. Dayicioglu V, Sahinoglu Z, Kol E, Kucukbas M. The use of standard dose of magnesium sulphate in prophylaxis of eclamptic seizures: Do body mass index alterations have any effect on success? Hypertens Pregnancy 2003;22:257-65.

14. Nakazawa H, Uchida A, Minamitani T, Makishi A, Takamatsu $Y$, Kiyoshi $K$, et al. Factors affecting maternal serum magnesium levels during long-term magnesium sulfate tocolysis in singleton and twin pregnancy. J Obstet Gynaecol Res 2015;41:1178-84.

15. Vilchez G, Dai J, Lagos M, Sokol RJ. Maternal side effects \& fetal neuroprotection according to body mass index after magnesium sulfate in a multicenter randomized controlled trial. J Matern Fetal Neonatal Med 2018;31:178-83.

16. Tudela CM, McIntire DD, Alexander JM. Effect of maternal body mass index on serum magnesium levels given for seizure prophylaxis. Obstet Gynecol 2013;121:314-20.

17. Boriboonhirunsarn D, Lertbunnaphong T, Suwanwanich M. Correlation of magnesium levels in cord blood and maternal serum among pre-eclamptic pregnant women treated with magnesium sulfate. J Obstet Gynaecol Res 2012;38:247-52.

18. World Health Organization International Obesity Task Force. The Asian-Pacific perspective: redefining obesity and its treatment. Melbourne: Health Communications Australia; 2000.

19. Lu JF, Nightingale $\mathrm{CH}$. Magnesium sulfate in eclampsia and pre-eclampsia: pharmacokinetic principles. Clin Pharmacokinet 2000;38:305-14.

20. Hall DG. Serum magnesium in pregnancy. Obstet Gynecol 1957;9:158-62.

21. McGuinness GA, Weinstein MM, Cruikshank DP, Pitkin RM. Effects of magnesium sulfate treatment on perinatal calcium metabolism. II. Neonatal responses. Obstet Gynecol 1980;56:595-600.

22. Cruikshank DP, Pitkin RM, Donnelly E, Reynolds WA. Urinary magnesium, calcium, and phosphate excretion 


\section{Obstetrics \& Gynecology Science}

Vol. 64, No. 1, 2021

during magnesium sulfate infusion. Obstet Gynecol 1981;58:430-4.

23. Reynolds A, Slattery S, Byrne S, Neary E, Müllers S, Kent $E$, et al. Timing of administration of antenatal magnesium sulfate and umbilical cord blood magnesium levels in preterm babies. J Matern Fetal Neonatal Med 2019;32:1014-9.

24. Elliott JP, Radin TG. Serum magnesium levels during magnesium sulfate tocolysis in high-order multiple gestations. J Reprod Med 1995;40:450-2.

25. Marom-Haham L, Mazaki-Tovi S, Zilberman I, Kalter A, Haas J, Sivan E, et al. Disparity in post-treatment maternal circulating magnesium sulfate levels between twin and singleton gestation: Is this the missing link between plurality and adverse outcome? J Perinat Med 2015;43:585-90. 